\author{
УДК 629.762
}

Бъчков А. С. ${ }^{1}$, Нечипоренко О. Ю. ${ }^{2}$

${ }^{1}$ Государственный научно-исследовательский экспертно-криминалистический центр МВД Украины. Украина, г.Киев

${ }^{2}$ Государственное предприятие «АНТОНОВ». Украина. г. Киев

\title{
АНАЛИЗ ЭФФЕКТИВНОСТИ ПРИМЕНЕНИЯ ГАЗОТЕРМИЧЕСКИХ ПОКРЫТИЙ ДЛЯ ДЕТАЛЕЙ АВИАЦИОННОЙ ТЕХНИКИ
}

\begin{abstract}
Проведен анализ эффективности защитных покрытий, формируемых газотермическими методами напыления. Рассмотрены особенности нанесения покрытий из порошковых материалов газопламенным, плазменным и детонационным напылением. Показаны преимущества высокотемпературных защитных покрытий для суперсплавов, а также износостойких и коррозионностойких газотермических покрытий для повышения эксплуатационных характеристик деталей авиационной техники. [dx.doi.org/10.29010/081.11]
\end{abstract}

Ключевые слова: газотермические порошковые покрытия; эксплуатачионные характеристики; детали авиационной техники.

Для защиты объектов авиационной техники от воздействия различных факторов в процессе их эксплуатации применяют разнообразные покрытия, среди которых одними из наиболее эффективных являются покрытия, получаемые газотермическими и ионно-плазменными методами напыления.

К газотермическим методам напыления относятся газопламенное, плазменное и детонационное напыление покрытий из порошковых материалов. Одной из существенных особенностей газотермического напыления является возможность управления составом, структурой и, соответственно, свойствами покрытий за счет применения различных порошковых композиций с широким интервалом соотношения компонентов (металлов, сплавов, оксидов, боридов, нитридов, сульфидов, графита, твердых смазок и так далее) [1-2]1).

В основе процесса газопламенного напыления лежит пластификация порошка в высокотемпературном источнике тепла (ацетилен-кислородном пламени) и нанесение его газовыми потоками на предварительно подготовленную поверхность. Преимуществами данного метода являются высокая производительность процесса, локальность обработки, незначительное влияние на подложку, возможность нанесения покрытий на изделия больших размеров, отсутствие сочетаний материалов покрытия и положки. В зависимости от назначения покрытия и детали, условий ее эксплуатации, кон- тактов сопрягаемых поверхностей используют газопламенное напыление порошка без последующего оплавления, с одновременным или последующим оплавлением. Технологический процесс газопламенного напыления состоит из трех основных этапов: нагрева поверхности детали до температуры 200-250 ${ }^{\circ} \mathrm{C}$; нанесения подслоя; нанесение основных слоев, позволяющих получить покрытия с необходимыми физико-механическими свойствами [3].

На прочность сцепления покрытия с основой влияют способ подготовки, параметры струйной обработки и время выдержки поверхности после обработки; предварительный подогрев, подслой, эффективная мощность пламени, параметры процесса распыления, материал покрытия и другие [3].

Процесс плазменного напыления заключается в инжекции материала покрытия в виде порошка заранее заданного состава в высокотемпературную плазменную струю, которая создается в плазмотроне. В плазменной струе частицы порошка плавятся и разгоняются по направлению к подложке. Расплавленная металлическая капелька «расплющивается» о подложку и растекается по поверхности. На структуру и свойства получаемого покрытия влияют такие параметры процесса как степень предварительного подогрева, характеристики плазмотрона, расстояние от плазмотрона до рабочего тела и тому подобное [4].

1) Ниже в значительной степени использован материал, изложенный в нашей монографии [10]. 
Преимуществами метода плазменного напыления являются:

- высокая производительность процесса;

- большое количество параметров, обеспечивающих гибкое регулирование процесса напыления;

- регулирование в широких пределах качества покрытий, в том числе получение особокачественных покрытий при ведении процесса с общей защитой;

- высокий КИМ (0,3-0,8);

- возможность комплексной механизации и автоматизации процесса;

- широкая доступность метода;

- достаточная экономичность [1].

Для плазменного напыления пригоден любой материал, который можно изготовить в виде порошка необходимых фракций, хотя для оптимизации процесса плавления частиц порошка с разной температурой плавления может потребоваться некоторая модификация конструкции плазмотрона [4].

Главный недостаток процесса плазменного напыления состоит в том, что он является процессом «прямой видимости», то есть способным наносить покрытия лишь на открытые участки подложки, не затененные со стороны источника осаждаемых частиц. При обработке деталей сложной формы это ограничение создает проблемы в регулировании толщины покрытия из-за эффекта «затенения» - полного или частичного блокирования потока осаждаемых частиц порошка на одну часть детали другой ее частью, находящейся на линии прямой видимости от источника и заслоняющей от него эту область подложки. Такая проблема решается за счет сложного перемещениям обрабатываемой детали и плазмотрона при нанесении покрытия [4].

При детонационном напылении порошок транспортируется к обрабатываемой поверхности с помощью ударной волны, возникающей в результате взрыва смеси газов (ацетилена, водорода и других) с кислородом и обеспечивающей скорость перемещения частиц порошка 800-1300 м/c. В peзультате соударения частиц с поверхностью выделяется тепло, способствующее образованию прочного сцепления частиц с подложкой и между собой. Данный метод позволяет получать беспористые покрытия из материалов с температурой плавления выше температуры взрыва. Размеры и форма изделий в этом случае не ограничены и определяются техническими возможностями устройств для их перемещения в процессе нанесения покрытий, а также размерами звукоизолированного бокса [1, 5].

Преимуществами метода детонационного напыления являются высокое качество напыленных покрытий (пористость $\Pi \leq 1 \%$, прочность сцепления более $10 \mathrm{MПа);} \mathrm{возможность} \mathrm{напыления}$ покрытий на холодные изделия $\left(T_{\text {изд }} \leq 200{ }^{\circ} \mathrm{C}\right)$; умеренный нагрев изделий при их напылении
$\left(T_{\text {из }} \leq 2050{ }^{\circ} \mathrm{C}\right)$; достаточно высокая производительность и широкая номенклатура напыляемых материалов; невысокая чувствительность к состоянию исходной поверхности напыления [1].

В практике напыления используются как однородные порошки различных материалов, так и гетерогенные порошки сложной структуры - композиционные, а также их механические смеси [6].

Широкое применение механических смесей порошков для нанесения покрытий обусловлено простотой и дешевизной их приготовления: они могут перемешиваться на любом оборудовании или спекаться с последующим дроблением. Однако основным недостатком их является сегрегация компонентов при смешивании, транспортировании из дозирующих устройств, а также в процессе нанесения, что приводит к неравномерности структуры, увеличению пористости, снижению прочности и ухудшению эксплуатационных характеристик покрытия [7].

Композиционный порошок - порошок сложного состава, каждая частица которого состоит из макрообъемов нескольких компонентов, отличающихся по химическому составу, и идентична по качественному составу всем остальным [7].

По сравнению с механическими смесями при напылении композиционных порошков обеспечиваются следующие преимущества:

- защита основного материала ядра частицы от взаимодействия с газовой струей $(W C-N i)$;

- получение гетерогенных мелкодисперсных структур с равномерным распределением компонентов в покрытии $(W C-B N-N i)$;

- экзотермическое взаимодействие, способствующее нагреву порошка и улучшению условий формирования покрытий $(N i-A l)$;

- образование принципиально новых фазовых и структурных составляющих из диссоциируемых материалов $(\mathrm{W}-\mathrm{CuO})$;

- образование покрытий из материалов, самостоятельно не формируемых покрытий $(C-N i)$;

- повышение прочности капсулированных порошков ( $W C-B N-N i)$;

- повышение плотности $(\mathrm{MgO}-\mathrm{Ni})$, теплопроводности $\left(\mathrm{Al}-\mathrm{Al}_{2} \mathrm{O}_{3}\right)$ и текучести порошков;

- повышение КИМ;

- расширение номенклатуры порошков [2].

Создание и применение газотермических порошковых покрытий позволяет устранить разрыв между требованиями авиационной техники к конструкционным материалам и свойствами классических сплавов [7].

Высокотемпературное покрытие для суперсплавов представляет собой металлический, керамический или комбинированный поверхностный слой, способный предотвратить или замедлить прямое взаимодействие материала подложки с потенциально агрессивной окружающей средой. Поврежде- 


\section{CИCTEMbITC 4/2017}

ние материала при таком взаимодействии может проявляться в виде его окисления или коррозии, а также снижения механических свойств подложки за счет диффузиозного насыщения сплава вредными элементами при высоких температурах [4].

Покрытия на суперсплавах применяют для узлов и деталей высокотемпературных секций газовых турбин. Потребность в таких покрытиях возникла в 50-х годах прошлого века при производстве авиационных двигателей, когда стала очевидной несовместимость требований к составу материала для улучшения его высокотемпературной прочности и достижения оптимальной степени защиты от воздействия высокотемпературной окружающей среды. Повышение рабочей температуры вызывало интенсивное окисление никелевых и кобальтовых суперсплавов, применявшихся для изготовления рабочих и направляющих лопаток турбин. Необходимость решения проблемы защиты материалов от окисления в авиационных двигателях привела к разработке специальных (алюминидных) покрытий, некоторые из которых применяются до сих пор [4].

Однако такие покрытия оказались неэффективными при так называемой горячей коррозии. Горячая коррозия (коррозия, модифицированная присутствием на поверхности сплавов слоя осадка, что приводит к изменению характера взаимодействия данного сплава с окружающей средой) происходит в газовых турбинах. Уровень коррозионного разъедания материалов в значительной степени зависит от вида и чистоты используемого топлива, а также качества подаваемого в зону горения воздуха. Природа горячей коррозии такова, что вызываемое ее разъедание почти всегда приводит к более существенной деградации сплавов, чем «обычная» коррозия в такой же газовой среде, но без поверхностного модифицирующего слоя осадка. Это привело к разработке покрытий других типов, предназначенных специально для защиты от горячей коррозии. Позже был обнаружен еще один механизм разъедания, известный как низкотемпературная горячая коррозия. Для его подавления потребовалось разработать покрытия совсем другого состава, чем для защиты от классической горячей коррозии. Таким образом, различные покрытия разных классов и технологии их нанесения разрабатывались в соответствии с ужесточением требований, предъявляемых к материалам, при расширении области их применения [4].

На выбор покрытия влияет много факторов. Основной причиной применения покрытия является необходимость защиты материала подложки от вредного воздействия окружающей среды. При выборе покрытия следует учитывать все возможные эффекты, связанные с воздействием как самого покрытия, так и процесса его нанесения, на механи- ческие или теплофизические свойства суперсплава, включая влияние взаимной диффузии элементов между покрытием и подложкой во время работы при высоких температурах. Технология нанесения покрытия зависит от геометрии обрабатываемой детали, поскольку некоторые методы позволяют обрабатывать лишь открытые участки детали. Также на выбор конкретного типа покрытия всегда влияет его стоимость $[4,9]$.

В настоящее время наиболее распространенными методами нанесения оверлейных (внешних) покрытий на суперсплавы являются физические осаждения из паровой фазы (PVD-процесс) и плазменное напыление [4].

Хотя сама технология плазменного напыления покрытий не нова, однако ее применение в вакуумируемых камерах низкого давления является относительно новым процессом. Для многих современных покрытий, содержащих химически активные элементы типа $A l$ и $C r$ (например, покрытие $\mathrm{MeCrAlY}$, где $M e$ - металл), технология плазменного напыления при низком давлении позволяет минимизировать образование оксидных дефектов в структуре свеженапыленных покрытий. Преимуществом процесса при низком давлении является более высокие скорости напыляемых частиц порошка и расширенная область распыления. Покрытия также можно наносить и в защитной атмосфере инертного газа. Адгезия плазменных покрытий с подложкой обеспечивается последующей термической обработкой.

По сравнению с PVD-процессом метод плазменного напыления гораздо более гибок с точки зрения управления композиционным составом покрытия, поскольку не зависит от давления паров элементов, входящих в состав покрытия [4, 10].

Наиболее широко для защиты от окисления применяют оверлейные покрытия состава $\mathrm{NiCoCrAlY}$. Добавка Co в базисный NiCrAlY состав, кроме некоторого повышения стойкости к воздействию внешней среды, также улучшает пластичность покрытия.

Еще одним преимуществом NiCoCrAlY-покрытий при высокотемпературном применении является их более высокая температура плавления, практически не зависящая от состава и свойств подложки. При этом плавление диффузионной зоны при более низкой, чем для объема самого оверлейного покрытия, температуре не происходит. Оверлейные покрытия выдерживают температуру $1288^{\circ} \mathrm{C}$. Однако высокая температура плавления оверлейных покрытий сопровождается их очень низкой высокотемпературной прочностью, что может приводить к термоусталостному растрескиванию при циклических условиях работы [4].

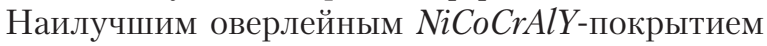
для работы в условиях горячей коррозии являются композиции на основе Со с относительно высоким 
отношением содержания $C r$ и $A l$. Покрытия на основе $\mathrm{Ni}$ (или $\mathrm{NiCo}$ ) и $\mathrm{Fe}$ эффективны при работе в окислительных средах и средах, вызывающих достаточно слабую горячую коррозию. Примером $\mathrm{MeCrAlY-покрытия} \mathrm{с} \mathrm{хорошим} \mathrm{сопротивлением}$ горячей коррозии является покрытие состава Co $-29 \mathrm{Cr}-6 \mathrm{Al}-0,3 \mathrm{Y}$, на поверхности которого, несмотря на относительно высокое содержание $\mathrm{Cr}$, образуется $\mathrm{Al}_{2} \mathrm{O}_{3}$. Обычно с увеличением соотношения концентраций $\mathrm{Cr}$ и $\mathrm{Al}$ стойкость к горячей коррозии возрастает, но одновременно несколько ухудшается сопротивление окислению. Среди оверлейных покрытий, защитные свойства которых обеспечиваются наличием на поверхности пленки $\mathrm{Al}_{2} \mathrm{O}_{3}$, наибольшей стойкостью к горячей коррозии обладают покрытия с максимально возможным для данного уровня механических свойств содержанием $C r$, в которые добавлены $Y, C r, P t$ и $H f[4,10]$.

Другой подход к разработке оверлейных покрытий, стойких к горячей коррозии, заключается в использовании $S i$ либо в качестве верхнего слоя для двух- или многослойных покрытий, либо как главного оксидообразующего элемента в покрытиях типа NiCrSi [4].

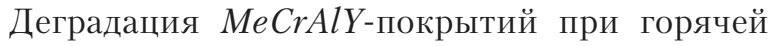
коррозии характеризуется наличием сульфидов и оксидов в объеме покрытия. Как правило, появление обогащенных хромом сульфидов предшествует образованию внутренних оксидов. В итоге происходит обеднение покрытия такими необходимыми для образования защитной оксидной пленки элементами, как $A l$ и $C r$, что приводит к разрушению покрытия.

Опыт применения некоторых $M e C r A l Y$-покрытий первого поколения свидетельствует о возможности их длительной эксплуатации. За счет увеличения толщины покрытия, что возможно при использовании технологий нанесения оверлейных покрытий, повышается долговечность деталей с покрытиями в коррозионных условиях. Оверлейные

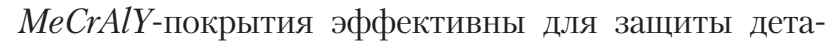
лей, работающих в условиях горячей коррозии при не слишком жестком термоциклировании [4, 10].

Оверлейные покрытия с относительно высоким содержанием $\mathrm{Cr}$ (более 30 \%), включая покрытия типа $\operatorname{Me} C r X$ и $M e C r A l Y$, относятся к покрытиям, защитное действие которых обусловлено преимущественным образованием $\mathrm{Cr}_{2} \mathrm{O}_{3}$. Все покрытия из высокохромистых сплавов на основе $\mathrm{Co}, \mathrm{Ni}$ и $\mathrm{Fe}$ могут служить эффективной защитой против низкотемпературной горячей коррозии. Однако из-за возможного локального повышения температуры некоторых зон конструкций в процессе работы и необходимости защиты их как от высоко-, так и от низкотемпературной коррозии, более предпочтительными являются высокохромистые покрытия на основе Co $[4,10]$.
В настоящее время широкое применение получили теплозащитные барьерные покрытия (ТЗБП), представляющие собой многослойную систему, состоящую из изолирующего керамического внешнего покрытия (верхний слой) и металлического внутреннего покрытия (связующий слой) между керамикой и подложкой. Первоначально большинство ТЗБП наносили методом плазменного напыления $\mathrm{Me} C r A l Y$ на воздухе, в настоящее время также применяют плазменное напыление при низком давлении. Шероховатость поверхностей как связующего металлического, так и верхнего керамического слоев, наносимых методом плазменного напыления, способствует хорошей адгезии их между собой $[4,10]$.

Назначение керамического слоя - обеспечить тепловую изоляцию металлической подложки, чтобы температура ее поверхности не превышала максимально допустимое значение. В зависимости от теплопроводности керамики, толщины покрытия и тепловых нагрузок на деталь, определяемых особенностями ее конструкции и системой охлаждения, градиент температуры по толщине покрытия может достигать несколько сот градусов. В качестве керамического слоя часто применяют $\mathrm{ZrO}_{2}$, имеющий очень низкую теплопроводность и достаточно высокий (для керамики) температурный коэффициент линейного расширения (ТКЛР). Однако при нагреве выше температуры $1170{ }^{\circ} \mathrm{C}$ в $\mathrm{ZrO}_{2}$ происходит переход от моноклинной к тетрагональной структуре, сопровождающийся объемными изменениями (4-6 \%), которые могут приводить к отслаиванию керамического слоя от подложки. Исключить такие изменения можно путем сдвига фазового перехода в область более низких температур, вплоть до комнатных, за счет стабилизации тетрагональной фазы в $\mathrm{ZrO}_{2}$ при добавках в него $\mathrm{MgO}, \mathrm{CaO}, \mathrm{Y}_{2} \mathrm{O}_{3}$ и оксидов Р3М (PSZ частично стабилизированный $\mathrm{ZrO}_{2}$ ) [4, 10].

Хотя верхний слой из $\mathrm{ZrO}_{2}$ и обеспечивает требуемую тепловую защиту, однако он не является серьезным барьером для переноса кислорода. Основным назначением металлического связующего слоя является защита подложки от агрессивной внешней среды, так как интенсивное образование оксидов на границе раздела «металл - керамика» может вызывать отслаивание керамики $[4,10]$.

Следует отметить, что в ТЗБП действует множество источников деформации материала покрытия, обусловленных наличием остаточных напряжений, возникающих уже в процессе нанесения покрытия; различием ТКЛР керамики и металлов; окислением и коррозией связующего слоя; фазовыми превращениями в керамике при термоциклировании; градиентами температур в деталях, работающих в горячей зоне газовых турбин; возможной механической деформацией деталей в процессе эксплуатации. Как следствие, керамический слой 


\section{CИCTEMbITC 4/2017}

часто приобретает склонность к отслаиванию непосредственно по границе раздела керамики с металлическим связующим слоем [4].

В связи с этим проводятся разработки таких технологий нанесения покрытий, которые позволяли бы получать менее чувствительную к деформации структуру керамического слоя и более стабильный слой металлического связующего покрытия с хорошими механическими свойствами и повышенной стойкостью в агрессивной окружающей среде. Это может быть достигнуто за счет более жесткого контроля фазовой структуры нанесенного покрытия или намеренного введения дефектов в покрытие в процессе его нанесения. Фазовый состав покрытия весьма чувствителен к составу и структуре исходного порошка, а также к изменениям параметров процесса плазменного напыления (температуры подложки, расстояния от плазмотрона до рабочего тела и так далее). Введение дефектов в керамический слой осуществляют при строгом контроле над этими параметрами, что необходимо для получения требуемой пористости и/или желательного развития микротрещин в осаждаемом слое. Получению необходимой дефектной структуры также способствуют некоторые технологические операции, проводимые уже после нанесения покрытия, в том числе отжиг и закалка [4].

Применение связующих слоев с повышенной окислительной и коррозионной стойкостью также приводит к улучшению рабочих характеристик покрытия. Защитное действие связующего слоя можно дополнить за счет поверхностной обработки (лазерного глазурования керамики), а также выбора таких параметров процесса плазменного напыления перед его окончанием, которые приводили бы к формированию плотного поверхностного слоя, предотвращающего абсорбцию агрессивных солей [4].

В настоящее время в ТЗБП используют, как правило, $\mathrm{ZrO}_{2}$, частично стабилизированный 6-8 \% $\mathrm{Y}_{2} \mathrm{O}_{3}$. Значительное понижение температуры поверхности деталей горячих секций двигателя самолета, достигаемое благодаря ТЗБП, позволяет исключить проблему деформации деталей за счет ползучести [4, 8].

Испытания покрытий из $\mathrm{ZrO}_{2}$, стабилизированного 6 и $20 \% \mathrm{Y}_{2} \mathrm{O}_{3}$ или $21 \% \mathrm{MgO}$, показали, что наибольшей термостойкостью обладают покрытия с повышенной пористостью (15-20 \%) и имеющие микротрещины. В качестве подслоя использовали сплав $\mathrm{Ni}-21 \mathrm{Co}-18 \mathrm{Cr}-13 \mathrm{Al}-0,7 \mathrm{Y}[6]$.

Исследована коррозионная стойкость плазменных покрытий из $\mathrm{ZrO}_{2}$, стабилизированного 8 и $20 \% \mathrm{Y}_{2} \mathrm{O}_{3}$, и $\mathrm{MgO} \cdot \mathrm{ZrO}_{2}$. Покрытия наносили на сплавы $\mathrm{Ni}$ - Co поверх промежуточного слоя из сплава $\mathrm{Ni}-20 \mathrm{Co}-11 \mathrm{Al}-0,4 \mathrm{Y}$. Испытания проводили в потоке продуктов сгорания жидкого топлива с незначительными добавками $\mathrm{Na}, \mathrm{V}, \mathrm{P}, \mathrm{Ca}, \mathrm{Fe}$ и $\mathrm{Mg}$ в условиях циклического нагрева продолжительностью 500 циклов по 1 ч. Температура газов составляла $1150{ }^{\circ} \mathrm{C}$, температура подложки - 800, 850 и $900{ }^{\circ} \mathrm{C}$. Установлено, что при низкой температуре подложки большинство составов покрытий выдерживают 500 циклов. При более высокой температуре стойкими являются составы на основе $\mathrm{ZrO}_{2}$, стабилизированного $8 \% \mathrm{Y}_{2} \mathrm{O}_{3}$, а также составы с $\mathrm{MgO} \cdot \mathrm{ZrO}_{2}$. $\mathrm{C}$ увеличением содержания примесей в топливе при температуре $800{ }^{\circ} \mathrm{C}$ продолжительность 500 циклов выдерживает только состав с $8 \% \mathrm{Y}_{2} \mathrm{O}_{3}$ [6].

Покрытия из смеси $\mathrm{MeCrAlY}$ и оксида $\mathrm{ZrO}_{2}$, стабилизированного $\mathrm{Y}_{2} \mathrm{O}_{3}$, нанесенные на турбинные лопатки, испытывали в потоке газа при температуре $1010{ }^{\circ} \mathrm{C}$. Разрушение покрытий происходило преимущественно на границе раздела «металл керамика». Сравнительные испытания при температуре $1037-1260{ }^{\circ} \mathrm{C}$ показали, что покрытие из $\mathrm{ZrO}_{2}$ в смеси со сплавом $\mathrm{CoCrAlY}$ имеет в два раза большую жаростойкость, чем в случае использования в качестве металлической составляющей сплава NiCr. Теплозащитный слой из керамики $\mathrm{MgO} \cdot \mathrm{ZrO}_{2}$ в смеси со сплавом $\mathrm{NiAl}$ позволяет в три раза повысить срок службы камеры сгорания [6].

Покрытия из $\mathrm{ZrO}_{2}$ частично стабилизированного добавками $\mathrm{MgO}$, повышают срок службы деталей газотурбинных двигателей (ГТД) на 50 \%, сокращают количество необходимого для охлаждения воздуха, а также создают предпосылки для повышения температуры на входе в турбину. Двойные покрытия $\mathrm{Al}_{2} \mathrm{O}_{3}-\mathrm{PSZ}$ наносят на рабочие поверхности сопел реактивных двигателей. На поверхности камер сгорания реактивных двигателей наносят покрытия из PSZ или тройные покрытия $\mathrm{NiCr}-\left(\mathrm{NiAl}-\mathrm{ZrO}_{2}-\mathrm{MgO}\right)-\left(\mathrm{ZrO}_{2}-\mathrm{MgO}\right)$ (третий слой - внешний). За счет нанесения покрытий из $\mathrm{NiCr}$-сплавов и $\mathrm{ZrO}_{2}$, стабилизированного $\mathrm{MgO}$, на различные детали воздушно-реактивных двигателей (лопатки турбины и компрессора, камера сгорания, подшипники и другие) удается повысить ресурс их работы с 4000 до 24000 ч [11].

Таким образом, эволюция разработки покрытий для суперсплавов прошла путь от простых алюминидных покрытий в начале 50 -х годов прошлого века до $\mathrm{MeCr} A l Y$-покрытий, и завершилась созданием ТЗБП. Покрытия типа MeCrAlY с высоким содержанием $A l$ обеспечивают достаточно высокое сопротивление окислению при высоких температуpax, а применение ТЗБП позволяет достичь наивысшей температуры сгорания топлива в турбине, недостижимой никаким другим способом. Применение высокохромистых покрытий типа $\mathrm{MeCrAlY}$ и $\mathrm{Me} C r \mathrm{X}$ совместно с алюминидами металлов обеспечивает максимальную стойкость к горячей и низкотемпературной коррозии [4].

Конструкция современных летательных аппаратов и авиадвигателей представляет собой много- 
функциональную систему взаимосвязанных конструктивных элементов, узлов и механизмов с большим количеством подвижных и номинально-неподвижных соединений, детали которых во время эксплуатации подвергаются трению и износу. Так, только в комплекте шасси широкофюзеляжного транспортного самолета количество подвижных соединений превышает 390, а общее количество узлов трения самолета с учетом потенциальной возможности малых относительных перемещений во всех соединениях может определяться 6-7-значным числом. Несмотря на значительные достижения в технологии авиастроения, износ и повреждения деталей в узлах трения остаются одним из основных факторов, снижающих эксплуатационную надежность и ограничивающих ресурс авиационной техники [9, 12].

Износ рассматривают как одно из проявлений поверхностного разрушения деталей, которое происходит под действием сил трения. Характерным признаком износа, отличающим его от других процессов поверхностного разрушения (в том числе коррозии), является наличие силового влияния на поверхность детали [12].

Одним из наиболее сложных видов износа в авиационных конструкциях является фреттингкоррозия. Такой вид износа характерен для деталей номинально-неподвижных соединений, работающих в условиях циклических и вибрационных нагружений, которые для большинства конструктивных элементов летательных аппаратов являются постоянно действующими факторами [12].

Эффективным способом защиты деталей авиационной техники от коррозии и износа (в парах трения, при газо- и гидроабразивном износе, усталостном разрушении поверхностных слоев, фреттинг-коррозии, коррозионно-механическом износе) являются газотермические порошковые покрытия. Благодаря применению газотермического напыления период между профилактическими осмотрами авиационных газовых турбин увеличился с 4000 до 24000 ч. Так, в двигателях самолетов Boeing содержится 600 деталей с плазменными покрытиями, а в двигателях самолетов Concorde, Airbus, Mirage плазменное напыление используют для защиты 90 узлов [6, 10].

Плазменные покрытия на основе $W C$ со связкой Co или $\mathrm{Ni}$ применяют в «холодной» зоне ГТД $\left(T<540{ }^{\circ} \mathrm{C}\right)$. Для напыления используют порошки литого сплава $W C-12 C o$, спеченных сплавов $W C-$ $12 C o$ и $W C-17 C o$, механической смеси $W C-12 C o$ с самофлюсующимся никелевым сплавом и композиционным порошком $80 \mathrm{Ni}-20 \mathrm{Al}$. Такие покрытия отличаются высокой стойкостью к изнашиванию абразивными частицами и в условиях фреттингкоррозии, а также имеют высокую прочность сцепления при умеренных температурах [6].

Для защиты от фреттинг-коррозии при температурах до $540{ }^{\circ} \mathrm{C}$ также применяют плазменное напыление сплавов на основе $\mathrm{Cu}$ (алюминиевые бронзы, сплавы $\mathrm{Cu}-\mathrm{Ni}$ и $\mathrm{Cu}-\mathrm{Ni}-\mathrm{In}), \mathrm{Ni}-\mathrm{Al}$, никелевых самофлюсующихся сплавов в смеси с $M o$, композиционным порошком и твердыми сплавами [6].

Для повышения износостойкости деталей в условиях фреттинг-коррозии применяют покрытия, полученные плазменным напылением с использованием плакированных никелем порошков $\mathrm{Cr}_{3} \mathrm{C}_{2}$ и $\mathrm{TiC}$ (КХН-30 состава $70 \mathrm{Cr}_{2} \mathrm{O}_{3}-30 \mathrm{Ni}$, КТН-35 состава $65 \mathrm{TiC}$ - 35Ni, КТН-50 состава $50 \mathrm{TiC}-50 \mathrm{Ni})$, а также сложнолегированного эвтектического сплава на основе железа ВТН состава $\mathrm{Fe}-(\mathrm{Cr} ; \mathrm{Ni} ; \mathrm{V} ; \mathrm{Ti}, \mathrm{C}, \mathrm{B})$ [12].

Для защиты от высокотемпературной фреттинг-коррозии $\left(T=540-840{ }^{\circ} \mathrm{C}\right)$ применяют плазменные покрытия из сплавов $N i-A l$ и $C o$ (в том числе с добавкой $Y$ ), композиционных порошков $N i-A l$, смесей на основе $C_{3} C_{2}$. Эффективными в таких условиях являются покрытия гетерогенного типа - твердые включения, равномерно распределенные в более мягкой вязкой матрице [6, 10].

Плазменное напыление используют при нанесении Мо на гнездо подшипников вала ротора агрегата вспомогательного тока из титанового сплава; твердого сплава $W C$ - Co - на посадочное место подшипника насоса; сплава $\mathrm{Cu}-\mathrm{Ni}$, легированного In - на замки вентиляторных лопаток; покрытия из $W C$ толщиной 0,25 мм (после шлифования) - на наружный цилиндр переднего колеса шасси самолета и так далее [6].

Обмотки генераторов самолетов работают в условиях термических и механических ударов, сильной вибрации в интервале температур от -60 до $+490{ }^{\circ} \mathrm{C}$. Этим условиям удовлетворяют плазменные покрытия из $\mathrm{Al}_{2} \mathrm{O}_{3}$, наносимые на никелированную медную проволоку, используемую для обмоток [6].

Помимо функциональности следует отметить еще один важный аспект, связанный с использованием покрытий. Так как в процессе эксплуатации деталей авиационной техники на их поверхности образуются дефекты в результате износа, механических повреждений, коррозии и растрескивания, то для дальнейшей работы таких деталей необходимо восстановление их первоначальных размеров. Своевременный и качественный ремонт деталей методами газотермического напыления позволяет предотвратить возникновение неисправностей и отказов, продлить ресурс, обеспечить возможность безопасной эксплуатации авиационной техники в течение всего назначенного ресурса [6, 12].

Ремонту напылением подвергают детали из сплавов $\mathrm{Al}, \mathrm{Mg}, \mathrm{Ti}, \mathrm{Ni}$ и сложнолегированных сталей. Выбор материала покрытия и способов напыления зависят от условий работы, характера дефекта, ТКЛР основы и покрытия, возможности манипулирования деталью, величины износа и так далее $[9,10,12]$. 


\section{CИCTEMGITC 4/2017}

В процессе ремонта авиационной техники значительное количество деталей, которые отбраковываются по причине существенного износа, составляют детали, изготовленные из титановых сплавов. Это обусловлено высокой склонностью к схватыванию и низкой износостойкостью титановых сплавов в условиях трения. Как правило, такие детали входят в состав номинально-неподвижных соединений, износ которых вызван развитием фреттинг-коррозии [12].

Среди существующих способов газотермического напыления в авиаремонтном производстве для восстановления деталей из титановых сплавов наиболее широко используются детонационное и плазменное напыление. Детонационное напыление эффективно для восстановления деталей с небольшой площадью дефектных поверхностей, таких как бандажные полки рабочих лопаток компрессора ГТД, локальные места выработки некоторых корпусных деталей и так далее. С помощью детонационного напыления формируются наиболее плотные покрытия с низкой пористостью и высокой адгезионной и когезионной прочностью [12].

Плазменное напыление применяют для восстановления как малогабаритных с небольшой площадью деталей, так и крупногабаритных деталей со значительной площадью дефектов. Однако по сравнению с детонационными покрытиями плазменные покрытия имеют большую пористость, меньшую адгезионную и когезионную прочность.

Газоплазменное напыление для восстановления титановых деталей авиационной техники не нашло широкого применения по причине низкой плотности и адгезионной прочности покрытий [10, 12].

Для восстановления деталей из титановых сплавов (например, рабочих лопаток компрессора для некоторых типов ГТД) методом детонационного напыления применяют механические порошковые смеси $W C-C o$ и $W C-N i[12]$.

При ремонте изношенных деталей авиационной техники широко применяют плазменные покрытия из $\mathrm{Mo}$, интерметаллического сплава ВКНА (ПН75Ю23В) на основе $N i_{3} A l$ с добавками тугоплавких металлов, порошкового материала ПС-12НВК-01, композиционных порошковых материалов на основе $\mathrm{Cr}_{3} C_{2}, \mathrm{TiC}$ и другие [12].

Материал ПС-12НВК-01 представляет собой механическую смесь порошков из никелевого самофлюсующегося сплава $\mathrm{NiCrBSi}$ и карбида WC (60\%). $\mathrm{B}$ такой смеси твердый, износостойкий, но хрупкий компонент WC (75 HRC) соединен с более пластичным материалом NiCrBSi (54-62 HRC), формирующим матрицу покрытия [6].

C помощью методов газотермического напыления с применением соответствующих материалов рабочим поверхностям деталей одновременно с восстановлением можно придать и более высокую износостойкость.

Среди деталей системы механизации крыла самолетов характерным дефектом является износ опорной поверхности реек выпуска-уборки закрылков и предкрылков в местах контакта с роликами каретки. На различных типах самолетов рейки механизации крыла изготавливают из высокопрочных титановых сплавов или сталей. Рабочие поверхности стальных реек электролитически хромируют. Учитывая существенную технологическую сложность таких деталей и, соответственно, их высокую стоимость, разработка технологических процессов поверхностного упрочнения и восстановления реек во время ремонта является актуальной задачей [12].

Так, в конструкции механизма управления закрылками транспортного самолета рейки были изготовлены из титанового сплава ВТ22 в отличие от предыдущих конструкций из стали 40ХНМА, что дало возможность значительно увеличить ресурс и исключить коррозию и скалывание хромового покрытия, характерных для стальных деталей. Тем не менее, при наработке около 6000 полетов (больше назначенного ресурса самолета) в зонах размещения каретки при взлете, посадке и крейсерском режиме были обнаружены недопустимые лунки износа от роликов каретки (рис. 1). Механизм такого износа фреттинг [13].

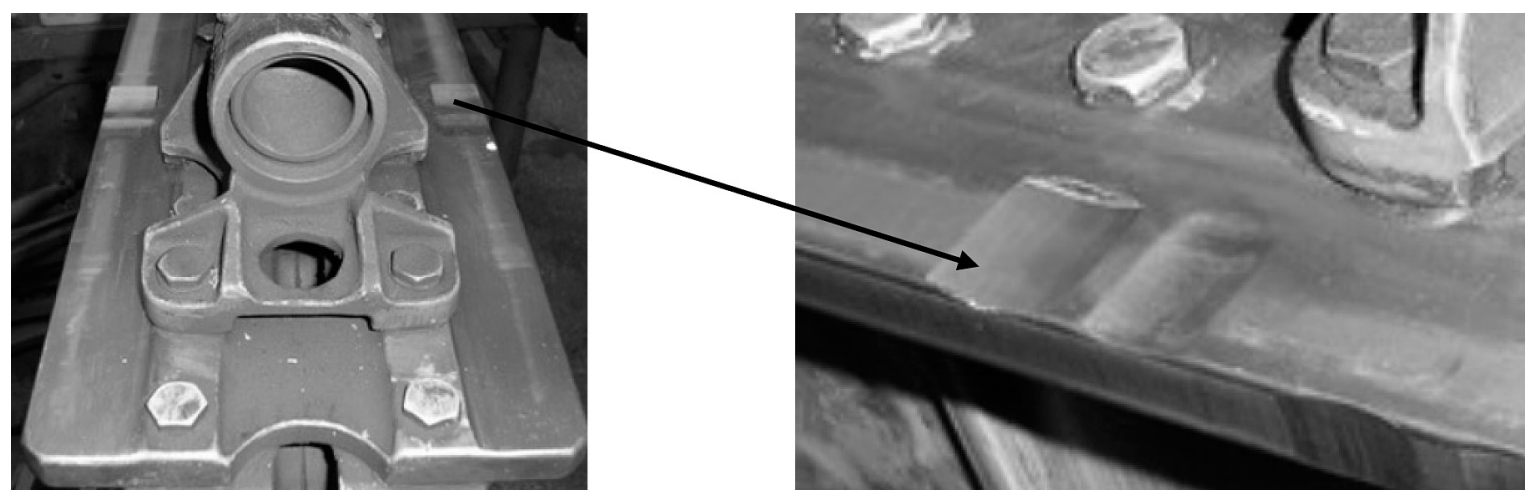

Рис. 1. Общий вид рейки управления закрылками с лунками износа [13] 
Эффективным технологическим методом восстановления реек из титанового сплава ВТ22 является детонационное и плазменное напыление покрытий из износостойких материалов и $M o$. Такая технология обеспечивает возможность восстановления локальных областей износа рабочих поверхностей реек с одновременным повышением их износостойкости [12-13].

Для ремонта деталей ГТД методами газотермического напыления применяют такие материалы как $A l$, сплав $\mathrm{Co}-25,5 \mathrm{Cr}-10,5 \mathrm{Ni}-7,5 \mathrm{~W}$, композиционный порошок $80 \mathrm{Ni}-20 \mathrm{Al}$ (для получения жаростойких слоев и подслоя), СНГН, ВН-30 (WC - 30Ni), $\mathrm{BK}-15$ ( $W C-160 C o), C r_{2} C_{3}-N i$ (для получения износостойких слоев) [6].

Детали реактивного двигателя восстанавливают газотермическим напылением сплава $\mathrm{WC}-\mathrm{Co}, \mathrm{Cr}_{2} \mathrm{C}_{3}$, Mo сплава на основе Co с добавкой $\mathrm{Ni}, \mathrm{Cr}, \mathrm{W}$. Опыт применения плазменного напыления при ремонте реактивных двигателей показал, что длительность ремонта снижается в среднем на 50 \%, а долговечность деталей, восстановленных плазменным методом, повышается по отдельным узлам (детали турбокомпрессоров, форсунки и другие), продолжительность восстановления сокращается с 30-60 до $1-2,3$ ч $[6,10]$.

Для восстановления деталей из магниевых и алюминиевых сплавов применяют плазменные покрытия из $\mathrm{NiAl}$ и $\mathrm{Cr}_{2} \mathrm{C}_{3}$ со связкой, прочность сцепления которых составляет 84-85 и 76-81 МПа, соответственно [6].

Плазменный метод напыления широко используется при ремонте таких деталей как поворотные цапфы шасси, втулки, буксы. Применение покрытия не только повышает срок службы детали, но и позволяет ее многократно восстанавливать. Срок службы детали при этом определяется усталостью или ползучестью самого материала, а не его поверхностными свойствами [6].

\section{Выводы}

Целенаправленное создание поверхностных слоев методами газотермического напыления является эффективным методом защиты и повышения эксплуатационных свойств деталей авиационной техники. Использование износостойких, коррозионностойких, жаростойких, теплоизоляционных и других видов газотермических порошковых покрытий позволяет существенно сократить потери металла, расход ресурсов на их возмещение и дает возможность повысить качество, надежность и долговечность деталей и узлов авиационных конструкций при относительно невысоких технологических затратах.

\section{Литература}

[1] Порошковая металлургия и напыленные покрытия: Учеб. для ВУЗов [Текст] / В.Н. Анциферов, Г.В. Бобров, Л.К. Дружинин и др. - Под ред. Б.С. Митина. - М.: Металлургия, 1987. - 792 с.

[2] Газотермическое напыление композиционных порошков [Текст] / А.Я. Кулик, Ю.С. Борисов, А.С. Мнухин, М.Д. Никитин. - Л.: Машиностроение, Ленинград. отд-е, 1985. - 199 с.

[3] Молодык Н.В. Восстановление деталей машин: Справ. [Текст] / Н.В. Молодык, А.С. Зенкин. - М.: Машиностроение, 1989. - 480 c.

[4] Суперсплавы II: Жаропрочные материалы для аэрокосмических и промышленных энергоустановок [Текст]: пер. с анг. / Под ред. Ч.Т. Симса, Н.С. Столоффа, У.К. Хагеля. В 2-х кн. / Под ред. Р.Е. Шалина - М.: Металлургия, 1995. - 384 с.

[5] Шведков Е.Л. Словарь-справочник по порошковой металлургии. [Текст] / Е.Л. Шведков, Э.Т. Денисенко, И.И. Ковенский. - К.: Наук. думка, 1982. - 272 с.

[6] Борисов Ю.С. Плазменные порошковые покрытия [Текст] / Ю.С. Борисов, А.Л. Борисова. - К.: Техніка, 1986. - 223 c.

[7] Черновол М.И. Упрочнение и восстановление деталей машин композиционными покрытиями: Учеб пособие [Текст] / М.И. Черновол. - К.: Вища школа, 1992. - 79 c.

[8] Лакиза С.М. Діаграми стану систем як наукова основа для створення нових теплозахисних покриттів [Текст] / С.М. Лакиза, Я.С. Тищенко, Л.М. Лопато // Порошк. металургія, 2014. - № 4/6. - С. 92-99.

[9] Быков М.Н. Выбор и назначение директивной технологии нанесения покрытий силовых авиаконструкций по критериям долговечности и экономической эффективности: дис. ...канд. техн. наук: 05.07.02 / Быков Михаил Николаевич. - К.: Нац. авиац. ун-т, 2013. - 205 с.

[10] Порошковые материалы для авиационной и ракетно-космической техники [Текст] А.А. Коцюба, А.С. Бычков, О.Ю. Нечипоренко, И.Г. Лавренко К. : КВИЦ, 2016. - 304 с.

[11] Калинович Д.Ф. Диоксид циркония: свойства и применение [Текст] / Д.Ф. Калинович, Л.И. Кузнецова, Э.П. Денисенко // Порошк. металлургия. - 1987. № 11. - С. 98 - 103.

[12] Організація та трибології авіаремонтного виробництва [Текст] / А.П. Кудрін, О.І. Духо та, М.В. Кіндрачук, Г.М. Зайвенко. - К. : НАУ, 2015. - 212 с.

[13] Конструкционные материалы в самолетостроении [Текст] / А.Г. Моляр, А.А. Коцюба, А.С. Бычков, О.Ю. Нечипоренко. - К.: КВИЦ, 2015. - 400 с. 
Bychkov A. S. ${ }^{1}$, Nechyporenko O.Yu. ${ }^{2}$

${ }^{1}$ State Scientific and Research Expert-Forensic Center of the MIA of Ukraine. Ukraine, Kiev

${ }^{2}$ ANTONOV, State-owned Enterprise. Ukraine, Kiev

\section{ANALYSIS OF THE EFFECTIVENESS OF THE USE OF GAS-THERMAL COATINGS FOR AIRCRAFT COMPONENTS}

The efficiency of protective coatings, formed by gas-thermal spraying methods, is analyzed. The features of applying coatings from powder materials with gas-flame, plasma and detonation spraying are considered. The advantages of high-temperature protective coatings for superalloys, as well as wear-resistant and corrosion-resistant gas-thermal coatings for improving the operational characteristics of aviation components parts are shown. [dx.doi.org/10.29010/081.11]

Keywords: gas-thermal powder coatings; operational characteristics; aircraft components.

\section{References}

[1] Powder metallurgy and sprayed coating: Textbook for High Schools [Text] / V.N. Antsiferof, G.V. Bobrov, L.K. Druzhinin etc. - Edited by B.S. Mitin. - M. : Metallurgy, 1987. - 792 p.

[2] Gas-thermal spraying of composite powders [Text] / A.Ya. Kulik, Yu.S. Borisov, A.S. Mnukhin, M.D. Nikitin. L. : Mashinostroyeniye, Leningrad. Branch, 1985. - 199 p.

[3] Molodyk N.V. Repair of machine parts: Reference Book [Text] / N.V. Molodyk, A.S. Zenkin. - M. : Mashinostroyeniye, 1989. - $480 \mathrm{p}$

[4] Superalloys II: High-temperature alloys for aerospace and industrial power plants [Text] : trans. from Eng. / Edited by Chester T. Sims, Normal S. Stoloff, William C. Hagel. In 2 books / Edited by R.E. Shalin. - M. : Metallurgy, 1995. $384 \mathrm{p}$.

[5] Shvedkov E.L. Dictionary-reference for powder metallurgy [Text] / E.L. Shvedkov, E.T. Denisenko , I.I. Kovensky. K. : Naukova Dumka, 1982. - 272 p.

[6] Borisov Yu.S. Plasma powder coating [Text] / Yu.S. Borisov, A.L. Borisova. - K. : Technika, 1986. - 223 p.

[7] Chernovol M.I. Hardening and repairing of machine parts with composite coatings: Textbook [Text] / M.I. Chernovol. - K. : Vishcha Shkola, 1992. - 79 p.

[8] Lakiza S.M. State diagrams of systems as a scientific basis for creating new thermal protection coatings [Text] / S.M. Lakiza, Ya.S. Tishchenko, L.M. Lopato // Powder Metallurgy, 2014. - № 4/6. - P. 92-99.

[9] Bukov M.N. Selection and appointment of directive technology for coating aircraft power structures on the basis of the criteria of durability and economic efficiency: disser. ... PhD in Engineering Sciences: 05.07.02 / Bukov Mikhail Nikolayevich. - K. : NAU, 2013. - 205 p.

[10] Powder materials for aviation and rocket-space technology [Text] / A.A. Kotsyuba, A.S. Bychkov, O.Yu. Nechyporenko, I.G. Lavrenko. - K. : KVITS, 2016. - 304 p.

[11] Kalinovich D.F. Zirconia: properties and applications [Text] / D.F. Kalinovich, L.I. Kuznetsova, E.P. Denisenko // Powder Metallurgy, 1987. - № 11. - P. 98-103.

[12] Organization and tribology of aircraft repair production [Text] / A.P. Kudrin, A.I. Dukhota, M.V. Kindrachuk, G.M. Zayvenko. - K. : NAU, 2015. - 212 p.

[13] Structural materials in aircraft construction [Text] / A.G. Molar, A.A. Kotsyuba, A.S. Bychkov, O.Yu. Nechyporenko. K.: KVITS, 2015. - 400 p. 